\title{
Bringing The Body Back In: The SOCIAL Construction of EMBOdIED SEXUAL IDENTITIES
}

\author{
ANNA M. ZajICEK, Chris SHIELDS, AND Joe L. Wright \\ University of Arkansas
}

In spite of many notable attempts to overcome one-dimensional approaches to sexuality, ${ }^{1}$ debates over its meaning have been dominated by extreme views. ${ }^{2}$ At first, it has been argued that the issue of sexuality belongs to the domain of body, biology and sexual nature. ${ }^{3}$ Since the 1980 s, this view has been challenged by social constructionists who argue that both sexual nature and sexual identity are socially constructed. ${ }^{+}$Recently, an extreme argument, stating that sexuality must be viewed as a radically disembodied "empty category" of sexual identity "constituted through discursively constrained performative acts" ${ }^{\prime \prime}$ has became popular. The more recent approaches have moved the debate in the right direction, away from biological determinism. Ultimately, however, they tend to discount the perceptions of people who, based on their bodily experiences of sexuality, developed rather rigid sexual attractions and/or feel that they were born with a certain sexual nature. ${ }^{6}$ Although sexuality is a lived, bodily experience and a central organizing principle of one's sense of self, attempts to understand it in relation to actors' accounts of their inner experiences of their bodies have been sparse.?

In this context, the sociology of the body represents an attempt to acknowledge the importance of the body in everyday life and the role embodiment plays in contemporary culture. From this perspective, our physical bodies cannot simply be separated from the process of identity formation and our negotiations of social position. Rather, the body is intimately connected to the understandings that we formulate about ourselves and our surroundings. ${ }^{8}$ Specifically, the bodily 
responses that inform our sexual orientations are always experienced culturally. Yet our cultural experiences of sexuality are also shaped by our bodily responses. ${ }^{9}$ Thus, one of the main contributions of the sociology of the body to our understanding of sexuality is that it recognizes, at least in principle, the importance of including the interplay between the body and social forces and meanings in our accounts of sexuality formation.

Recent scholarship on the body has been criticized for displaying "a marked ambivalence towards the material body and a tendency to privilege the body as a metaphor." 10 Yet, "[b]odies are not simply abstractions...but are embedded in the immediacies of everyday, lived experience. Embodied theory requires interaction between theories about the body and analysis of the particularities of embodied experiences and practices." ${ }^{11}$ Existential sociology, which focuses on the actor's total existence, provides a corrective to these problems. With regard to the relationship between body and society, existential sociology posits that the social actor is an aggregate of his/her existence, which includes not only the physical body but also our perceptions, emotions, history, and participation in the ongoing stream of social situations. In this paper, we build on the sociology of the body and existentialism to explore the relationships between sexual bodies and sexual identities ${ }^{12}$ and to contribute to a fuller understanding of the processes of sexuality formation from the actor's perspective. Specifically, by centering respondents' bodily experiences and the situations in which they find themselves, this study not only provides an insight into the processes of sexual identity formation and its fluid nature, but also into the possibility that sexual nature can be stable for some and changeable for others. In this context, we introduce the concept of "embodied sexual identity," which can be successfully applied to grasp the different facets, stable and unstable, rigid and malleable, of sexuality as well as the complex relationships between individual experiences of the body and sexual identities.
Dominant Conceptualizations of Sexuality

\section{Essentialist Conceptualizations of Sexuality}

Until recently, debates over sexuality have been dominated by two theoretical perspectives-essentialist and constructionist. ${ }^{13}$ Essentialist thought consists of two strands. The first perspective, cultural essentialism, assumes that human sexuality has universal forms and expressions, which have an objective existence independent of a social or cultural context. ${ }^{14}$ From this position, categories of sexual identity are social facts that do not change over time or across cultural boundaries. The evidence, it is argued, is provided by the fact that heterosexual and homosexual behaviors exist in every culture and society, among every race and religious group, and throughout history. For example, after reviewing historical data concerning homosexuality, Bullough ${ }^{15}$ concludes that "homosexuality has always been with us; it has been a constant in history, and its presence is clear." Likewise, based on their study of four societies, Whitam and Mathy ${ }^{16}$ state that "the universal, parallel development of homosexual populations points to an explanation in terms of biology, rather than the social-construction."

Biological essentialism is implied in the argument that sexual orientation is independent of socio-cultural forces. This approach focuses on the biological/genetic factors that determine an individual's sexual nature and identity. For example, $\mathrm{LeVay}^{17}$ concludes that genetic factors, not social or environmental conditions, are the most promising area for exploration. He also argues that we must reject Locke's concept of the tabula rasa because the genetic blueprint we are born with determines individual development. ${ }^{18}$

\section{Social Constructionism}

Since the 1980s, the essentialist approach has been challenged by social constructionism, which can be divided into two theoretical strands. The first strand, consists of so-called empty categories con- 
structionism ${ }^{19}$ and post-structuralism. ${ }^{20}$ The second, more moderate version of constructionism. is represented by Weeks. ${ }^{21}$ We will discuss these perspectives in turn.

The "empty-categories" constructionism, greatly influenced by labeling theory, focuses on how sexual identity categories are socially constructed or invented.22 The proponents of this position move beyond the notion that sexual identity is not objective to argue that "[t]here is no such thing as a homosexual, no such thing as a heterosexual. Everyone has homosexual and heterosexual desires and impulses and responses." ${ }^{33}$ The question is not about how people are born. Rather, it is "Are there people who even remotely fit these categories?" This version of constructionism offers a radical problematization of sexual categories.

Post-structuralism takes this radical problematization of sexual categories in a different direction. First, it shifts the focus away from the relationship between individuals and existing categories. Second, it asserts that sexuality must be analyzed at the level of the institutional discourses that materialize and objectify it. This occurs through the operation of discourses on sexuality, regulatory norms, and identity categories. ${ }^{2+}$ Specifically, Butler ${ }^{25}$ suggests that sexuality is not a fixed condition of the body but a process whereby dominant heterosexual norms materialize various sexual identities, but not in the same way: "[T] he heterosexual imperative enables certain sexed identifications and disavows other identifications."

Despite their contributions to our understanding of sexual identity construction, both approaches can be seen as reductionist: they limit our understanding of sexuality by eliminating from theoretical discourse the role actors' experiences of their physical bodies play in sexual identity. ${ }^{26}$ This is especially apparent among post-structuralists, who are uncompromisingly anti-empirical, "consider the subject to be a linguistic convention," 27 and see the body as one among many discursive fields. As a result, both perspectives ignore the material, physical body.
The moderate perspective acknowledges the existence of people who may fit existing categories, but it also tries to move away from the question of sexual nature. ${ }^{28}$ Also, it recognizes that there may be some aspects of human behavior that are not determined by existing discourses, even though the meaning of these behaviors is always socially mediated. In this manner, moderate constructionism preserves the presence of human agency, and grants the possibility of subjective personal identity and choices. For example, Weeks ${ }^{29}$ posits that in a society where homosexuality is stigmatized, "the adoption of lesbian or gay identity ...constitutes a political choice. These identities are not expressions of secret essences. They are self-creations, but they are creations on ground not freely chosen but laid out by history."

If identities are self-creations, this conceptualization allows the possibility that some people may think they have a sexual nature that cannot be changed or chosen, and therefore self-create themselves as agents with no choices as far as their sexual nature is concerned. At the same time, our sexual identities "are not so much about who we really are, what our sex dictates. They are about what we want to be and could be."30 Thus, in contrast to more extreme constructionism, Weeks does not deny the importance of subjectivity in the construction of sexual identity. Still, he does not systematically include this recognition in his theorizing. Instead, as Roscoe ${ }^{31}$ suggests, moderate constructionists "try to encompass" their understanding by ultimately resorting to society. By not dealing systematically with the question of how people experience their bodies and what meaning the relationship between sexual nature and sexual identity may have for them, this perspective ultimately privileges social forces over bodies. ${ }^{32}$

\section{Bringing The Body Back In: The Sociology of The Body and Existentialism}

The debate between constructionists and essentialists has many dimensions. On one level, the disagreement appears to be purely 
theoretical, with each side emphasizing a different explanation of how sexual identities are developed. Yet, in reality, the essentialist vs. constructionist argument is much more than a theoretical debate; it has crucial political implications. First, for some, the debate is over who has the power to define the reality and whose views will be used to identify or label a given group of people. ${ }^{33}$ Second, the argument is over the perils of confusing the vocabulary that we use to speak about the world with the objects that exist in that world, thereby mistaking our understanding as essential truths. ${ }^{3+}$ Third, the battle is also over the very meaning of sex. Some argue that sex is essentially a procreative act, and that any sexual conduct outside of that act is deviant, illegal, and illegitimate. ${ }^{35}$ Others have claimed that they could not have made bad choices in their sexuality if there is a genetic foundation for homosexuality. ${ }^{36}$ The end result is that essentialists and constructionists have been so busy vilifying each other that not enough attention have been given to the creation of a middle ground acknowledging the influence of both social and natural forces.

To date, Stein's study of the relationships between desire and the sense of self among lesbians is the most remarkable attempt to move beyond the essentialist-constructionist debate. Stein's effort is underlined by what she calls "a deeper conception of self-construction" which acknowledges that people "make identities-but not exactly as they please." 37 She creates a three-tier typology of the relationship between desire and the sense of self: the women who saw their personal identity as restricted by deep desires they have always felt; the women who talked about making choices and experiencing flexibility in selecting the objects of desire; and the women who combined the elements of the two. ${ }^{38}$ Despite these variations, many respondents in Stein's study were similar in that, at one point or another, they experienced a gap between their desires and how they identified themselves.

While Stein's typology is a decisive step toward a more adequate understanding of the relationship between deep desires and identi- ties, it has two limitations. First, Stein's typology emerged from the accounts of self-identified lesbians and bisexual women. This raises the question as whether the same relationships would emerge from the accounts of gay men or people who currently self-identify as heterosexual. Second, Stein's attempt to synthesize essentialist and constructionist approaches emphasizes the relationship between personal and social identities, but does not systematically address the question as to how actors representing a range of desires construct them in relation to their bodies, on the one side, and available social categories and norms, on the other.

The sociology of the body provides important insights that can help us to overcome the marginalization of the body in recent discussions of sexuality. This perspective starts from the assumption that we must understand the meaning of our bodies beyond the mere objectively observable parts (literally) that Western medicine has allowed. ${ }^{39}$ In this context, it is argued that our physical bodies cannot simply be separated from the process of identity formation and our negotiations of social position. Rather, the body is intimately connected to the understandings that we formulate about ourselves and our surroundings. ${ }^{+0}$ Specifically, the bodily responses that inform our sexual orientations are always experienced culturally, and our cultural experiences of sexuality tend to be shaped by our bodily responses. ${ }^{41}$ Thus, one of the main contributions of the sociology of the body to the constructionist-essentialist debate is that it recognizes the importance of the interplay of the body, social forces and meanings in sexuality formation.

From this position, those who focus on the body and biology are not automatically wrong. Neither are those who focus on social forces and cultural meanings. Rather, both sides have it right, in a way. To deny that evolution, biology, and the body are relevant to human sexuality flies in the face of what sexuality involves: the experience of pleasures through the use of bodies. However, to deny social construction's role in sexuality also denies that we are put into categories that 1) influence our behavior; 
2) structure our social environments and 3) that both reproduce and resist hierarchies of bodies, desires, and identities. ${ }^{+2}$ The sociology of the body is therefore about the use of our bodies as a means of resistance and as a means of control. At the same time, however, the sociology of the body tends to focus more on the symbolic aspects of the body than on "individuals' actual material bodies or their everyday interactions with their bodies and through their bodies with the world around them." +3

This weakness in the sociology of the body can be rectified by integrating some insights of the existential sociology, which is "the study of human experience in the world...in all its forms." "4+ The main focus of existential thought is on the actor seen as an aggregate of his/her embodied existence. Embodiment was a term coined by Gabriel Marcel, mainly as a critique of the Cartesian mind/body dualism. Marcel taught that we cannot be separated from our bodies. ${ }^{45}$ However, he also warned that we cannot see ourselves merely as bodies, because there does seem to be something else present beside flesh. ${ }^{+6}$ As an embodied person, "I feel, I sense, my existence. It is as body that I 'participated' directly in the being of the world. 'I exist', says Marcel, 'means not I think, not even I live, but I experience."' +7 In this context, the concept of embodiment includes not only the actor's physical body but also his or her perceptions, emotions, history, and participation in an ongoing flow of situations. This is an important point when considering an actor's belief in having a real sexual nature. The existence of sexual nature may not lend itself to rational/ objective analysis, but if an embodied subject experiences the existence of a sexual nature as real, then it becomes real in its consequences. Ritzer ${ }^{48}$ summarizes the existentialist concept of the embodied self as follows:

The self, to the existentialist, cannot be separated from the physical body in which it is found...Furthermore, the self is viewed not as a static structure but as a process, something constantly in a state of becoming. That is, the self is creative and spontaneous, strongly affected by its immediate situation. In this definition, the self is seen as at least partially problematic and situational.
Another useful existentialist concept is that of situation, which denotes the presence of permeable boundaries between the subjective agent and the surrounding world. By situation, Sartre meant the relation between a human being and his or her world and used it to address the dilemma of whether an actor fashions or is fashioned by society. ${ }^{49}$ Specifically, using the concept of situation, Sartre argued that an actor has the freedom to choose a course of action despite external forces. ${ }^{50}$ The current work is an elaboration on the sociology of the body through the integration of the above existentialist ideas taken from the works of two leading existentialists, Marcel and Sartre. This research adds to our understanding of how sexualities are formed by centering respondents' experiences of their bodies and by highlighting the diversity of these bodily experiences and their complex relationships to sexual identity. It is our contention that attending to both body and society is vital to gaining a fuller understanding how sexualities are formed.

\section{Description of Research}

The ideas discussed in this paper are part of an ongoing study, which the first and the second author began in 1997. Between October 1997 and February 1998, the second author conducted twelve interviews with people representing a wide range of sexual natures and identities. The interviews lasted on average one hour and focused on the respondent's sexuality and identity, i.e., the respondent's readings of their bodily responses to other people, their definitions of sexual nature, and how the respondent identifies him/herself (heterosexual, homosexual, bisexual, other, or none). Also, each respondent was asked why s/he identifies as such, and whether they have used the same sexual identification throughout their lives. If not, we asked what other identifications they had used.

We used a theoretical sample to facilitate our search for respondents who could help us explore the possible existence of sexual nature and its relationship to sexual identity from the actor's viewpoint. ${ }^{51}$ 
Theoretical sampling is used to assure the selection of "participants who are experiential experts" and to assure that the theoretically meaningful data is collected. ${ }^{52}$ Because theoretical sampling allows us to pre-specify cases so that the most theoretically important information is extracted from them, ${ }^{53}$ it is a very useful method of data collection when research involves sensitive subjects, such as sexuality, and difficult to reach populations, such as gays, lesbians, or bisexual people. Specifically, based on Stein's typology, we looked for respondents (1) who thought they had a sexual nature and those who thought they did not; (2) who projected different sexual natures; and (3) who either had or had not changed their sexual identities.

One of the main concerns with this study was locating respondents who would represent the different case-types and who were willing to discuss their sexuality on tape. Due to the intimate nature of questions, the second author tried to develop trust and a strong rapport with potential respondents before interviews were conducted. Toward this end, the potential respondents were contacted at least a couple of months prior to conducting the interviews. During that period the second author engaged the respondents in both public and private settings. The conversations involved discussing the research, the concerns respondents might have, and yielded preliminary information necessary to select respondents.

Since this research is exploratory in nature, deals with a sensitive topic, and entails population that is difficult to reach, we decided that it was the theoretical importance of the interviews, rather than their number, that mattered. As interviews progressed, we constructed a provisional list of cases illustrated in the interviews and, using the same contact strategy, sought respondents representing a new category or pattern. These category-patterns provided the data regarding the existence of sexual nature and its relationship to sexual identity from the actor's viewpoint. In this way, we interviewed between two to nine people in each category described by Stein, but, in contrast to her three-tier typology, we constructed four types of embodied sexual identities and observed eight processes of sexuality formation.
The first and the second author met several times to discuss observations and findings. Data were categorized according to conceptual themes or "sensitizing concepts" ${ }^{3+}$ which emerged from the interviews. We applied a systematic approach to the coding process, beginning with open-ended codes, selective coding to broaden, compare, and contrast findings, and, finally, axial coding as described by Strauss and Corbin ${ }^{55}$ from which our concepts arose. The concepts used to describe the processes underlying identity formation as well as embodied sexual identities arose from discussions between the first and the second author during coding of the data. These concepts are not meant to categorize people. Rather, they are meant to describe different processes underlying sexual identity formation and to emphasize the fluid nature of sexuality across different situations.

\section{Respondents}

Our research was conducted in a relatively homogenous, ninety percent white, university town in the South. The context of this research and its nature (i.e., sensitive topic and gaining access to a relatively invisible population), created some limitations for the sample, which consisted of seven white men and five white women. Also, respondents were relatively young, aged from 21 to 43 with a mean age of 28 ( 26.8 for females, and 29.2 for males). Each of the respondents had some level of postsecondary education. Six respondents-Brady, Peter, Sam, Alex, Bobby, and Cindy-had completed four-year degrees at a major university. ${ }^{56}$ In addition, Brady, Peter, and Cindy were pursuing a post-graduate education. Marsha and Alice were enrolled at a four-year college. Two respondents, Mike and Jan, had completed nursing and/or dental programs. The remaining respondents, Greg and Carol, had attended college for at least two years.

We also collected socio-economic data. Greg, Carol, and Cindy reported growing up in working-class families. The other nine respondents reported growing up in middle-class families. ${ }^{57}$ Each of the five in school at the time were also employed either part or 
full-time. Similarly, Sam, Alex, and Carol stated they were making arrangements to further their education, but only Carol was working at the time. The remaining respondents-Mike, Greg, Marsha, and Jan-were each gainfully employed in professional or skilled positions. Despite these limitations, we believe that our research, which emphasizes an interpretive understanding and theoretical meaning, can provide an insight into the complex nature of sexual identity formation. To put it differently, we believe that even partial and contextual knowledge can yield a meaningful and insightful understanding of reality.

\section{Research Findings}

\section{Sexual Nature}

We defined sexual nature as a physical sexual attraction one has for a particular sex (or both sexes) that the person believes he or she was born with and constructs for bim/ herself by using existing linguistic categories to interpret their bodily reactions to other people. Eight of the twelve respondents spoke of a sexual nature and were adamant they were born with one. Two respondents believed that they did possess an inveterate sexual nature, but could not commit as to whether they were born with it. But, when describing their sexuality, all ten respondents spoke of the unquestionable physical attractions they have had to a particular sex (or both sexes), which they believed they had no control over. The two remaining respondents (Peter and Alice) did not believe they possessed a sexual nature or any predisposition for sexual attraction for any sex.

Cindy exemplifies the first group of respondents who believed that they have an innate sexual nature:

I am heterosexual, I do believe I was born that way, I know it's not popular to say that, but I find men sexually attractive. A good-looking man makes my stomach stir and my knees weak. It goes beyond a choice, men just do something for me that women don't.
Cindy and Jan constructed their sexual nature by interpreting the physiological responses they have for men, women, or both.

All the male respondents who identified themselves as homosexual also stated they had a sexual nature. Statements by Sam and Brady best represent these accounts. Sam stated that, "[f]rom as far back as I can remember I have always been sexually attracted to men, I was married to a woman for three years, but I was always attracted to men...I was definitely born gay." Brady tells us:

Well, yes. I know that many gay men and women argue that it is not important to argue whether you were born one way or another, but I honestly feel that I was born gay. I have always been sexually attracted to males, and can honestly say that I have never been attracted to females, at least sexually. I mean, I appreciate feminine beauty, and I have slept with women, but I was never sexually attracted to them in the same way. My first sexual fantasy was about a man, and every sexual fantasy since has been.

Similar to Cindy and Jan, these men constructed their sexual nature by citing the innate sexual desire and physiological responses they had for the same sex. This latter group of respondents went a step further, though. Each had engaged in sexual activity with the opposite sex, and each described it in the same way: it didn't feel natural. Therefore, the subjective construction of their sexual nature occurred through a physiological attraction to men, accompanied by their reactions to sexual contact with women. As in previous cases, their sexual nature emerges as they filter the responses and attractions they feel through social definitions.

Other respondents' accounts of sexual nature suggest the possibility of a different experience of one's body. Bobby, one of the two self-identified heterosexual men, said he did not know whether he was born with a particular sexual orientation. However, similar to the respondents who professed a sexual nature, Bobby maintained that, based on his physical attraction to women, his "nature is heterosexual." Similarly, Carol, a self- 
identified lesbian, was not sure if she was born with a sexual nature, but stated that she had one because of her deeply felt attraction to and desire for relationships with women. Importantly, Carol refused to define her sexual nature in sexual terms only. She stated, "I do find men attractive, and can imagine the particulars [of sex]...but I just desire relationships with women...If it was just about sex, I guess I would say [that I'm] bisexual, but there is a lot more to it than sex."

Finally, two respondents, Alice and Peter, reported no sense of sexual nature at all. Alice stated that she does not have a sexual nature because she is able to control who she is sexually attracted to. Peter stated that he is not heterosexual, homosexual, or bisexual by nature because he desired both women and men. While this would indicate having a bisexual nature, Peter insisted that his sexuality is malleable and that he does not have a deep sense of his sexual orientation. Instead, he chooses to define his sexuality through the relationships he is involved in. This suggests that Peter, and Alice to some extent, construct their sexuality through their social identities.

The variability in how the twelve respondents experience their sexual nature suggests that there is no one way in which we experience our sexuality through our bodies. Some people's bodily experiences of sexuality can be relatively stable and restricted from the time they can remember. For others, their experience of sexuality appears to be still quite stable, but rooted in their intimate relations and social identities. Finally, some people's bodily experiences of sexuality suggest the absence of sexual nature or its great malleability and fluidity.

\section{Sexual Identities}

The responses recorded during the course of the interviews indicate that our respondents differentiated between their deeply felt attractions (sexual nature) and their self-conceptions (sexual identity). Their sexual identities included the manner in which they presented themselves to others. Specifically, the accounts of our respondents suggest an identification of the self with social sexual labels that may or may not correspond to sexual nature. The presence or absence of harmony between the two tells us a lot about "how people define their situation." 59

For some people, including those who talked about having a particular sexual nature, their sexual identity was defined in relation to the specific situations they found themselves in. For example, one respondent said:

$$
\begin{aligned}
& \text { I have exclusively identified myself as homosexual since the } \\
& \text { advent of AIDS. I wouldn't risk exposing a woman to HIV } \\
& \text { with having homosexual relationships. That's the first time in } \\
& \text { my life I stopped having anything to do with women. I totally } \\
& \text { quit having sex with women. Before that I had identified my- } \\
& \text { self as bisexual...I had identified myself as bisexual for my } \\
& \text { entire life... (Mike) }
\end{aligned}
$$

Another respondent also defined her sexual identity as relational and situational:

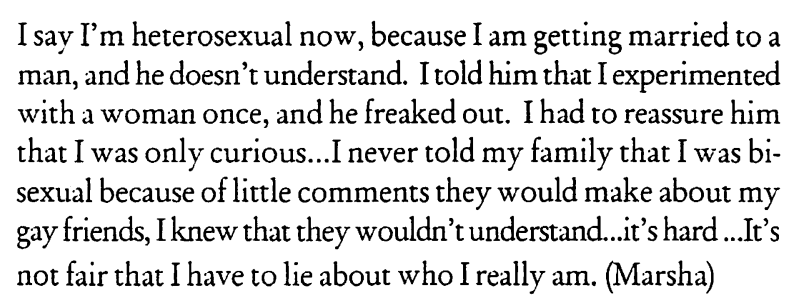
man, and he doesn't understand. I told him that I experimented with a woman once, and he freaked out. I had to reassure him that I was only curious...I never told my family that I was bisexual because of little comments they would make about my gay friends, I knew that they wouldn't understand...it's hard ...It's not fair that I have to lie about who I really am. (Marsha)

Mike's and Marsha's responses were quite similar to those of the other respondents who related that they had used more than one sexual identity during their lifetime. Marsha reported using two identities at the same time, as did two male respondents. Brady and Peter stated that they identified based on who they were talking to. Interestingly, the two identities that were interchanged were bisexual and heterosexual.

In general, the heterosexual identity was used in the workplace and among family, while the bisexual identity was used with close friends. Brady, who identified himself as a homosexual during 
the interview, gave the best explanation of why he once identified himself as heterosexual and bisexual interchangeably:

Well, I had told my parents that I was gay and they had a fit. Shit hit the fan, big time...I tried to convince myself that I was really bisexual, so that's what I told all of my gay friends, as well as myself. But to my parents, and everyone I worked with, I said that I was straight. I even told my girlfriend I was straight. (Brady)

Each of these statements reflects a presentation of self highly dependent upon the situation, and not necessarily upon one's sense of their sexual nature. But some respondents, not exclusively those whose sexual nature corresponds to the normative sexuality, talk about their decisions to label themselves based on their sexual nature. Consider the following:

I have always identified myself as straight (heterosexual), I never really thought about it, I mean I am attracted to men, I think women are pretty, but I don't want to have sex with them. For me, heterosexual is a reflection of who I am, some people might not see it that way (a decision to call oneself heterosexual), but for me, it's just who I am. (Jan)

Greg, who believed he was born gay, provided a similar account:

\begin{abstract}
I labeled myself as homosexual as soon as I knew what it meant, as long as I can remember. With women I always thought, she's pretty, but I never thought skinny or fat, with men, I always looked...I thought he's good-looking, nice personality, nice voice.

With men, I was always attracted to those things I looked for in a mate. (Greg)
\end{abstract}

Given the above accounts, it appears that the respondents identified themselves based on three situational criteria, (1) who they are disclosing to; (2) where they are (public or private); (3) who they have a relation with, and what their sexual nature is. For Jan and Greg, sexual identity was a reflection of their sexual nature. Cindy used the label heterosexual to identify herself because of her sexual nature and because of societal expectations. Conversely, Mike and Marsha both chose identities that do not reflect their sexual nature. In fact, their current identities appear to serve the purpose of disengaging them from the part of their sexual nature that they now find problematic. In addition, Marsha, Brady and Peter had previously used different identities depending on where they were and who they were interacting with. Alice had labeled herself "heterosexual" until she was seventeen at which time she had her first encounter with a woman. Since then she has used the label "bisexual" with everyone except her family. Alex, Brady, Carol, and Sam had each used other identifications earlier in life, but at the time of the interview, each identified as homosexual, reflecting what they defined as their sexual nature.

When our respondents discussed how they construct their identities, they often discussed whether or not their identities allowed them to express, hide, deny, explore, or transform their sexual natures. This led us to look more closely at the processes underlying the formation of sexual identity, the relationship between bodily experiences and identities, and the outcomes of these processes. Through the course of the interviews, the ways in which the respondents constructed the relationships between sexual nature and sexual identity emerged in three patterns: identitysymchronization, identity dis-synchronization, and identity reconciliation. ${ }^{60}$ Taken together, bodily experiences of sexuality, sexual identities, processes of sexual identity formation, and patterns of relationships between sexual nature and identity discussed in this paper provide a fuller view of sexuality than that provided by other perspectives. In what follows, we discuss the three patterns and the processes of identity formation underlying each pattern.

\section{Identity Synchronization}

Identity synchronization occurs when one's sexual nature appears to be innate, and a congruous sexual identity has always been used to express one's sexual nature. This can happen in two ways. Sometimes, using a sexual identity appears to be a natural 
decision consistent with the dominant cultural norms. For instance, among our respondents, Jan and Cindy made a "natural" decision when they identified themselves as heterosexual. The language they used to describe "being heterosexual" indicates that their decision to adopt a label was based on two factors: they believed they were born heterosexual and heterosexual identity is the norm. Neither respondent questioned whether she was heterosexual because each was exclusively sexually attracted to men. Cindy and Jan discussed this attraction as physiological, as an attraction that naturally occurred with men and not women. Both reported learning what sexual identity labels meant when they were pubescent, but neither questioned these labels because their intrinsic attraction to the opposite sex was in tune with the dominant norm. This relationship
can be called normative synchronization.

Normative synchronization occurs when one's embodied sexual nature is consistent with cultural norms, and that person identifies himself or herself using a dominant sexual identity label. Because this identity is in synchrony with the norm as well as the person's sexual nature, it allows the actor to express who he or she is. Still, the social actor does not view the adoption of this identity as a choice, but rather as the "natural" condition that happens to reflect the norms of the dominant society. The actor synchronizes identity and nature to the extent that differentiation between the two may all but disappear through the social norms that reward and "naturalize" the dominant identity.

Evidence of a "natural" decision to use a homosexual identity was also present. Greg stated that he identified himself as a homosexual "for as long [he] could remember." But, Greg's case is unique because he openly used an identity that was not consistent with social norms at an early age. When asked about identifying himself as a homosexual at such an early age, he said "I knew it wasn't the norm, but it [homosexual] described who I am. I am attracted to men." Even when social norms dictate that heterosexuality is expected, some people become aware of their "abject" sexual nature early on and never problematize it: "I never questioned whether I was gay, I just am."

Of course, as Stein's ${ }^{61}$ study suggests, for many gays, lesbians, or bisexuals the process of identity synchronization is more complex than it is for heterosexuals. While the sexual desires and sexual identities of heterosexual people typically correspond, Greg's experience may be atypical because many homosexual and bisexual people often experience an asynchrony between their bodily experiences and sexual identities. As we will discuss later, harmonizing the two often requires a considerable degree of what Stein calls "identity work." Th2 Thus, in a society where everyone is labeled as heterosexual by default, Greg's account acquires a different meaning from that of Jan or Cindy's. Greg underscores the fact that his sexual identity dis-synchronizes with dominant social norms, resulting in an "abject" sexual nature. Given the precariousness of his identity and nature, subversive synchronization occurs when an actor has a strong awareness of his or her embodied sexual nature from an early age and identifies himself or herself with a corresponding embodied identity despite its rejection by the dominant system.

\section{Identity Dis-Synchronization}

In contrast, identity dis-synchronization occurs when a person with a certain sexual nature uses an identity that does not express that nature or when a person with an ambiguous sexual nature decides to use a specific label because he/she is compelled to choose an identity that is consistent with social norms dominant in the community the person has primary relations with. While identity dis-synchronization could conceivably entail no change in identity, all the respondents in our study who currently identify in a manner incongruous with their sexual nature have used at least two different sexual identities. Regardless of whether identity dis-synchronization entails change or not, it appears that its meaning manifests in normative and subversive dis-synchronization. 
For example, both Marsha and Mike reported a bisexual nature. However, Marsha felt compelled to identify herself as heterosexual, and Mike identified himself as homosexual at the time of the interview. Two different paths led to these choices. Marsha was engaged, and she felt her fiancé would not accept her bisexuality. Marsha also noted that her family would never accept her bisexual nature. So despite the fact that she reported being equally attracted to both sexes, the threat of alienation and discrimination influenced her decision to identify as heterosexual and engage exclusively in heterosexual relationships. Likewise, Mike talked about a lack of legitimacy associated with his bisexual nature and the fact that both heterosexual and homosexual people tend to accuse bisexual people of riding the fence. In contrast to Marsha, however, Mike identified himself as homosexual. He claimed that this was due to his decision to not risk exposing women to HIV. ${ }^{63}$ Therefore, Mike made a decision based on social beliefs about the nature of the disease, choosing to identify himself as exclusively homosexual so that he would not inadvertently infect any of his female partners. Mike made this decision due to his stronger sexual attraction to men. He felt it unsafe and immoral to pursue sexual relationships that reflected his bisexual nature and chose to engage in only those relationships that reflected his stronger attractions.

Neither Marsha nor Mike felt it was fair to be forced into a decision on what type of relationship they wanted to engage in. They felt pressed to do so anyway. This is an example of how strongly the homo/heterosexual dichotomy can influence one's sexual identity. From these two cases emerged two variations of identity dis-synchronization: normative dis-synchronization and subversive dis-synchronization. We can see how tenuous the ideas of normative and subversive identities are from these examples. For instance, Mike's embodied identity is subversive only in relation to the dominant heteronormative system. Otherwise its subversive thrust is forfeited by the fact that his choice to use a homosexual identity represents his desire to conform with the norms of homosexual community and not with what he considers to be his true nature.
Similar to some of the women in Stein's study, Marsha and Mike felt compelled to choose either a heterosexual or homosexual identity, and engaged in "identity work" to make their sexual identity congruent with the social expectations or emergent definitions of situation. In the context of our focus on sexual nature, Marsha's and Mike's “identity work” has a contradictory meaning, which was not fleshed out by Stein. Specifically, "identity work" can result in a correspondence between sexual identity and cultural expectations, while leading to an asynchrony between sexual nature and sexual identity.

Two other examples of the contradictory meaning of "identity work" come from Peter's and Alice's accounts. Both Peter and Alice talked about being uncertain about having a sexual nature. Both reported identifying themselves based on current personal relationships. Alice, who talked about having an ambiguous sexual nature, defined her identity by referring to her emotional attraction to, and physical admiration of. women. At the same time, however, she spoke of her preference for relationships with men. In this case, social definitions associated with bisexuality allowed her to name her sexual identity. In contrast, Peter, who also claimed that he did not have a true sexual nature and felt sexual attraction to both men and women, defined his identity in a different way. During the interview, Peter identified himself as homosexual, bisexual and heterosexual. Peter is currently in a relationship with a woman, and identifies himself as exclusively heterosexual. Yet when he was in his last relationship with a man, he identified himself as exclusively homosexual. When he was not involved in a relationship, he identified himself as bisexual. This is an example of how relationships can be used by those who have an ambiguous sexuality to name and re-name an identity.

While one could argue that, in the absence of a definite sexual nature, both Peter and Alice's accounts represent examples of identity reflecting the ambiguous sexual nature, we submit that they should be seen as instances of identity dis-synchronization because, at least in theory, someone with no recognized sexual nature should identify as such. 
In sum, identity dis-synchronization occurred among the respondents who reported having a bisexual or ambiguous nature. Identity dis-synchronization is different from identity synchronization and identity reconciliation because, in the latter two, the person uses a sexual identity that reflects his or her sexual nature. In identity dis-synchronization, people are compelled to use an identity that does not reflect the totality of their sexual nature. Pressure to use this identity serves either to hide their sexual nature or to construct one where there is none.

\section{Identity Reconciliation}

Finally, identity reconciliation occurs when the actor uses an identity to first hide his or her sexual nature via identity dis-synchronization, then to enable it by way of identity synchronization. Bobby represents the first variation of identity reconciliation. While unsure of his innate sexual nature, he insisted that he was exclusively sexually attracted to women. He stated that he had identified himself as homosexual sometime ago, but that he now identifies as heterosexual. Why did Bobby formerly identify himself as a homosexual even though his real sexual nature is heterosexual? In answering this query, Bobby claimed that he always fitted all the physical stereotypes of a gay man and was often accused of being gay. His perception of himself was reinforced by the fact that he didn't share the "patriarchal" view of how men should treat women. He always felt that women should be equal, and believed this was another stereotype associated with gay men. Bobby came to believe that he was gay over time, even though he was sexually attracted to women. He stated that he was actually forced into it: "I was definitely stereotyped into believing I was a homosexual, I was pushed into it. I believed that I was homosexual, and at no time did I say, what in the f... am I doing?" Bobby began to identify himself as a heterosexual when he accepted the fact that sex with men did not feel natural. As he put it, "it didn't do anything for me." Bobby says that he is still confused about whether he was born heterosexual, but claims having heterosexual nature.
In contrast, Brady and Sam reported becoming aware of their sexual nature as a result of their sexual fantasies. To repeat Brady's words, his "first sexual fantasy was about a man, and every sexual fantasy since has been." But unlike Bobby, Brady and Sam identified themselves first as heterosexual, and then as bisexual:

I thought I was heterosexual, well, at least I wanted to be heterosexual. My parents always told me that everyone goes through a stage when they're curious about the same sex, they said that people who were mentally strong were able to overcome, and develop into heterosexuals, that only a few weak people remained homosexual. I had this really negative image of what gay was, and I assumed that I was just going through 'that stage' and pretty soon I would be straight. (Brady)

And:

Even though I knew I was gay, I didn't want to be known as a "faggot" dancer. When people found out what I did for a living, they naturally assumed I was gay, and not just gay, but a sissy, 'cause only sissies dance.' Kids can be cruel, and when I was growing up, they used to chase me and throw rocks at me, they called me sissy, and fag. I wanted to avoid that when I got older, so I got married, and told everyone I was straight. (Sam)

Both Brady and Sam elaborated on the strength of heteronormativity. ${ }^{6+}$ They spoke of their fear that if they identified themselves as homosexual, they would be discriminated against and experience alienation from their family and friends. As a result, for a period of time, they used a heterosexual identity, while being aware of their homosexual nature. Currently, both Brady and Sam identify as gay men.

Brady and Sam's desires to hide or ignore their bodily experiences, as well as Bobby's identification as homosexual despite his feeling to the contrary, are examples of the initial identity dissynchronization where the effect of identity in relation to sexual nature is to hinder access to it. However, as these examples suggest, some individuals do not stop there. Over time they may 
adopt an identity, which reflects what they define as their sexual nature. Because of the processes involved, this relationship can be called identity reconciliation. Identity reconciliation, as Stein's study suggests, requires a considerable degree of "identity work" and may eventually, but not necessarily, lead to the feeling of "coming home," that is, "identifying the desires...long affirmed in secret." "65 The eventual reconciliation of sexual nature and identity through "identity work" is evidence of the struggle that often occurs when they do not reflect one another. In sum, identity reconciliation occurs when one uses an identity that does not reflect his/her sexual nature, then at some critical turning point makes the decision to use the identity that reflects that nature. We can talk about normative reconciliation if it is related to the adoption of a normatively sanctioned identity. In turn, when it is related to the adoption of an "abject" identity, we can talk about subversive reconciliation.

\section{Conclusion: An Existentialist Alternative}

In this study, we have attempted to provide a fuller understanding of the meaning of sexuality by exploring the role of bodily experiences in the sexual identity formation and by examining relationships between sexual nature and sexual identity from the actors' viewpoints. We do not see our study as conclusive. Rather, we see it as a step toward a greater integration of bodily experiences into our understanding of sexuality. This integration can be helped by the recognition of the importance of the body in contemporary culture brought about by the sociology of the body and by the integration of the existentialist view of social actors as an aggregate of their existence. In what follows, we briefly discuss the implications of our study.

The contention of this paper is that our sexual identities are an admixture of bodily experiences in conjunction with situations. These experiences come from both the body and from our dealings with the world in which we live. The concepts of embodiment and situation allow us to view the formation of sexual identity at the crossroads of the body and society, yet as also involving an active self that is not subjected to either. Specifically, during the interviews, ten respondents stated that they had a sexual nature. While these respondents differed as to whether they thought they were born with a sexual nature, they all constructed their sexual nature by referring to physical and emotional attractions for a particular sex (or both), physiological responses to a particular sex (or both), or the desire for relationships (both physical and emotional) with a particular sex (or both). Similarly, those respondents who claimed to be unsure of having a sexual nature constructed an ambiguous "nature" used their bodily experiences or emotional attractions to explain their sexuality.

In terms of respondents' accounts of sexual identities, three respondents used only one identity throughout their life. The remaining nine used more than one identity, sometimes simultaneously. There were five primary factors involved in espousing an identity: (1) who one has sex with; (2) who one is related to-family approval or marriage; (3) where one is located-public or private; (4) the importance of social constraints-religion and normative structures; and, (5) what one's nature is. Although our respondents reported a number of factors when discussing what identity they used, their view of sexual nature and its relationship to cultural norms was omnipresent, resulting either in a reinforcement of perceived identity or an impetus to change their identities. It is through this relationship that embodied sexual identity emerges.

The concept of embodied sexual identity allows us to acknowledge that people have a subjective understanding of their sexuality. This understanding is related to people's bodily experiences and desires. Further, embodied sexual identity also encompasses the different relationships that may exist between sexual nature and sexual identity. Specifically, based on our study, three types of relationships are possible between sexual nature and identity: identity synchronization, identity dis-synchronization, and identity reconciliation. The first relationship occurs when one's sexual identity has always been 
used to express one's sexual nature. The second relationship, identity dissynchronization, occurs when a person with a certain sexual nature uses an identity that does not express that nature or when a person with an ambiguous sexual nature decides to use a specific label because he/she is compelled to choose an identity that is consistent with social norms dominant in the community the person has primary relations with. Finally, identity reconciliation occurs when the actor first uses identity dis-synchronization to hide his or her sexual identity and then uses identity synchronization to enable it.

We also observed that each relationship is underlined by subversive or normative processes of sexual identity formation. By attending to these processes we are able problematize the influence of power relations on sexuality. The crucial point is that embodied identities are also normative positions structured by domination. While there are both choices and set factors implicated in our bodily responses and our social standings, the underlying processes by which the sexual self is formed are not the same. The catch is that because these processes are in opposition to or in agreement with the dominant social norms, the meaning of identity synchronization is not the same for homosexual sexual nature as it is for the heterosexual one. Depending on how a person experiences their sexual nature, his or her identity may subversively or normatively expose it or conceal it, or it may subversively or normatively define it.

Thus, as our study empirically illustrated, by using the ideas developed within the sociology of the body and integrating existentialist concepts of embodiment and situation, we were able to provide a fuller understanding of sexuality than that provided by constructionist or essentialist frameworks. First, since in existentialism embodiment cannot be separated from situation, this concept allows us to grasp the processual nature of sexuality, including its stability for some people and its fluidity and instability for others. Second, by integrating people's experiences of the body, the concept of embodiment enables us to grasp the full meaning of identity formation, its normative and/or subversive aspects as well as the relationships between sexual nature and sexual identity, wherein sexual identity can serve as means of self-expression of our bodily experiences, their definition, or their concealment. In sum, embodied sexual identity integrates bodily experiences into our understanding of sexuality and emphasizes the fact that sexual identity is situational, but embodied in two senses: (1) it is always constructed by an embodied actor in relation to the situation of his/her existence; and (2) it acquires meaning in relation to a person's sexual nature, on the one hand, and the sexual identity through which it is articulated, on the other.

While other theoretical perspectives such as symbolic interactionism, dramaturgy, or phenomenology can also be used to account for processual and situational character of sexual identity, the processes of sexual identity formation, and the ways in which many people manipulate or manage their sexual identities, the existentialist concept of embodied sexual identity offers all this and more. We believe that the contribution this concept makes is related to the fact that, in addition to accounting for various aspects of sexual identity, including its processual and situational nature, in viewing the self as an aggregate of existence, it emphasizes the inseparability of the meaning of sexual identity from people's experiences of their physical bodies. Also, this concept allows us to view the sexual nature as stable or changeable and as rigid, absent, or ambiguous, depending on each actor's situated experiences of his/her body. Further, it allows as to account for the fact that while some actors' sexual identities appear to be a matter of choice, others feel that they have no choice in who they are sexually, that their sexuality has been predetermined by their biological make up. In either case, though, the embodied sexual identity goes beyond the dramaturgical concept of the presentation of self. Given our embodied sexual identities, the presentation of self through a given sexual identity occurs not only in relation to other, past and present, identities and the situations in which the actor finds him or herself, but also in relation to the bodily experiences of sexual nature. ${ }^{66}$ 


\section{REFERENCES}

Blumer, Herbert. 1969. Symbolic Interaction. Englewood Cliffs, NJ: Prentice Hall.

Bordo, Susan R. 1989. "The Body and the Reproduction of Femininity: A Feminist Appropriation of Foucault." Pp. 13-33 in Gender/Body/Knowel edge: Feminist Reconstructions of Being and Knowing, edited by A. M. Jaggar and S. R. Bordo. New Brunswick and London: Rutgers University Press.

Boswell, John. 1980. Christianity, Social Tolerance, and Homosexuality: Gay People in Western Europe from the Beginning of Christian Era to the Fourteenth Century. Chicago: University of Chicago Press.

- 1992. "Concepts, Experience and Sexuality." Pp. 133-175 in Forms of Desire: Sexual Orientation and the Social Constructionist Controversy, edited by E. Stein. New York: Garland Publishing.

Bullough, Vern L. 1979. Homosexuality: A History. New York: New American Library.

Butler, Judith. 1990. Gender Trouble: Feminism and the Subversion of Identity. New York: Routledge.

Cataldi, Sue L. 1993. Emotion, Depth, and Flesh: A Study of Sensitive Space (Reflections on Merleau-Ponty's Philosophy of Embodiment). Albany: State University of New York Press.

Cook, Gary A. 1993. George Herbert Mead: The Making of a Social Pragmatist. Urbana and Chicago: University of Illinois Press.

Cooley, Charles Horton. 1927. Social Process. New York: Charles Scribner's Sons.

Davis, Kathy. 1997. "Embody-ing Theory: Beyond Modernist and PostModernist Readings of the Body." Pp. 10-15 in Emodied Practices, edited by K. Davis. London: Sage.

Dimen, Muriel. 1995. "On "Our Nature": Prolegomenon to a Relational Theory of Sexuality." Pp. 129-152 in Disorienting Sexuality, edited by T. Domenici and R. C. Lesser. New York: Routledge.

Domenici, Thomas and Ronnie C. Lesser. 1995. "Introduction." Pp. 1-15 in Disorienting Sexuality, edited by T. Domenici and R. C. Lesser. New York: Routledge.

Douglas, Jack D. and John M. Johnson. 1977. Existential Sociology. New York: Cambridge University Press.

Eisele, Carolyn. 1979. Studies in the Scientific and Mathematical Pbilosophy of Charles S. Pierce, Edited by R. M. Martin. The Hague, Paris, New York: Mouton Publishers.
Epstein, Steven. 1991. "Sexuality and Identity: The Contribution of Object Relations Theory to a Constructionist Sociology." Theory and Society 20:825-873.

Frankenberg, Ruth. 1993. The Social Construction of Whiteness: White Women, Race Matters. Minneapolis: University of Minnesota Press.

Fraser, Mariam. 1999. Identity without Selfhood: Simone De Beautvoir and Bisexuality, Edited by J. C. Alexander. Cambridge: Cambridge University Press.

Katz, Jonathan. 1995. The Invention of Heterosexuality. New York: Dutton.

Kruks, Sonia. 1990. Situation and Human Existence: Freedom, Subjectivity, and Society. London: Unwin Hyman.

LeVay, Simon. 1991. "A Difference in Hypothalamic Structure between Heterosexual and Homosexual Men." Science August 30:1034-1037.

Morse, Janice M. 1994. “Designing Funded Qualitative Research." Pp. 220235 in Handbook of Qualitative Research, edited by N. K. Denzin and Y.S. Lincoln. Thousand Oaks: Sage.

Ponse, Barbara. 1978. Identities in the Lesbian World: The Social Construction of Self. Westport, Conn.: Greenwood.

Plummer, Ken. 1975. Sexual Stigma: An Interactionist Approach. London: Routledge \& Kegan Paul.

—. 1981. "Homosexual Categories." in The Making of the Modern Homo. sexual, edited by K. Plummer. New York: Routledge.

Richardson, Diane (ed.). 1996. Theorizing Heterosexuality. Philadelphia: Open University Press.

Ritzer, George. 1992. Sociological Theory. New York: The McGraw-Hill.

Roscoe, Will. 1988. "Making History: The Challenge of Gay and Lesbian Studies." Journal of Homosexuality 15:1-40.

Rosenau, Pauline Marie. 1992. Postmodernism and the Social Sciences: Insights, Inroads, and Intrusions. Princeton: Princeton University Press.

Ross, Ellen and Rayna Rapp. 1983. "Sex and Society: A Research Note from Social History and Anthropology." Pp. 13-73 in Powers of Desire: The Politics of Sexuality, edited by A. Snitow, C. Stansell, and S. Thompson. New York: Monthly Review Press.

Sheets-Johnstone, Maxine. 1992. "Charting the Interdisciplinary Course." Pp. 1-15 in Giving the Body Its Due, Suny Series, the Body in Culture, History, and Religion, edited by M. Sheets-Johnstone. Albany: State University of New York Press.

Stein, Arlene. 1997. Sex and Sensibility: Stories of a Lesbian Generation. Berkeley: University of California Press.

Stein, Edward. 1992a. "Conclusion: The Essentials of Constructionism and the Construction of Essentialism." Pp. 341-354 in Forms of 
Desire: Sexual Orientation and the Social Constructionist Controversy, edited by E. Stein. New York: Garland Publishers.

-—. 1992b. "Forms of Desire: Sexual Orientation and the Social Constructionist Controversy." New York: Garland Publishers.

Strauss, Anselm and Juliet Corbin. 1990. Basic of Qualitative Researcb: Grounded Theory Procedures and Techniques. Newbury Park, CA: Sage Publications.

Weeks, Jeffrey. 1993. "Sexual Identity Is a Strange Thing." Pp. 633-637 in Social Theory: The Multicultural and Classic Readings, edited by C. Lemert. Boulder, CO: Westview Press.

Whitam, Frederick and Robin Mathy. 1986. Male Homosexuality in Four Societies:Brazil, Guatemala, the Philippines, and the United States. New York:Preager.

\section{NOTES}

'See e.g., Epstein (1991) and Stein (1997)

-In this study, we use term sexuality in relation to sexual practices, erotic behaviors, feelings of attraction and affection, and gender performance. We define sexual nature as the physical sexual attraction for a particular gender that one believes s/he was born with or has been constrained by. The term sexual identity refers to the ways in which people identify, or do not identify, themselves as sexual beings in relation to social designations, such as heterosexual, homosexual, bisexual, etc. Since our conceptualization of sexual nature is similar to Plummer's (1981, p. 71-72) conceptualization of sexual orientation and Stein's (1997) discussion of deep desires, we use these terms interchangeably.

${ }^{3}$ (e.g., Bullough, 1979; Whitam and Mathy, 1986; LeVay, 1993)

${ }^{4}$ For this view of sexuality see Weeks (1993).

${ }^{5}$ (Butler 1990, p. viii)

'For a discussion of the problem of "under-determination" of desire by constructionism and some earlier attempts to address this issue see Epstein (1991, p. 830 -834) and Stein (1997, p.18-19)

${ }^{7}$ (see Stein 1997, p. 17)

${ }^{8}$ (Cataldi 1993, p. 60)

9 (Bordo 1989, p. 13; Ross and Rapp 1983, p. 51)

${ }^{10}$ (Davis 1997, p. 15)

"(Davis 1997, p.15)

12(1981)

${ }^{13}$ Each perspective consists of extreme or moderate strands. To preserve this diversity we will emphasize differences within each approach. However, since there are also differences of positions among authors who can be classified as representing the same strand, we chose to discuss only select representatives within each strand.

${ }^{1+}$ See for example Katz (1976), Bullough (1979), Whitam and Mathy (1986). However, in his later work, Katz (1995) has moved towards constructionist position.

$$
\text { is }(1979, \text { p. 62) }
$$

${ }^{16}(1986$, p. 16)

${ }^{17}(1993$, p. 137)

${ }^{18}(1993$, p. 138)

${ }^{19}$ (see Stein 1992a)

$20($ e.g. Butler 1990; 1996)

$21(1990 ; 1996)$

$\because$ (Stein 1992a)

${ }^{23}$ (Vidal, quoted in Stein 1992b: 342)

${ }^{2+}$ In this discussion we draw on Judith Butler (1990; 1996) who probably is the most important post-structuralist theorist of identity in the field of queer theory.

25 (1990; 1996, p. 3)

${ }^{26}$ See A. Stein (1997) for a similar criticism.

${ }_{27}$ (Rosneau 1992: 43)

${ }_{28}$ (see Weeks, 1993)

$29(1993$, p. 636)

${ }^{30}$ (Weeks 1993, p. 636; emphasis ours)

$31(1988$, p. 10)

32 Interestingly, even studies attuned to the concept of socially shaped identity provide essentialist conclusions. For instance, although in his conceptualization of homosexuality Boswell (1980) incorporates the concept of identity, he ultimately homosexuality Bosw in later work, Boswell suggests that being gay is a universal identity. Likewise, in his later work, Boswell (1992, p.135) suggests that society structures "opportunities for sexual expression and possibly even awareness of sexual feelings and desires." But, he also mentions and possibly even aw how hardly begins to address the problematic underlythat "[a]greeing on this, however, hardly begins to address the prual phenomena that ing questions, such as whether society is itself responding

are generic to humans and not created by social institutions."

${ }_{33}^{3}$ (Domenici and Lesser 1995, p. 1; Franke

3 (Domenici and Lesser 1995, p. 1; Fraser 1999, p. 5-6)

${ }_{36}$ (Dimen 1995, p. 129)

37 ibid. 19-20

${ }^{38}$ (Stein 1997: 47-64)

${ }^{39}$ (Sheets-Johnstone 1992, p. 5)

to (Cataldi 1993, p. 60)

+1 (Bordo 1989, p. 13; Ross and Rapp 1983, p. 51)

$+2(1989$, p. 13)

4.3 (Davis 1997, p.15)

${ }^{++}$(Douglas and Johnson 1977)

t5. (Kruks 1990, p. 33)

to (Kruks 1990, p. 33)

${ }^{47}(1990$, p. 32)

${ }^{+8}$ (1992, p. 517)

${ }^{+9}$ (Kruks 1990, p. 53)

so (Ritzer 1992, p. 516)

${ }^{51}$ (Morse 1994, p. 227) 
52 (Morse 1994, p. 227 and 229)

${ }^{53}$ (Stake 1994, p. 243)

it (Blumer 1969)

55 (Strauss and Corbin 1990)

i6 To protect the identity of our respondents we use pseudonyms.

${ }^{57}$ This distinction was based on what the respondents said about their parents' jobs and income levels while they were growing up

${ }^{58}$ Even though Bobby and Carol stated that they were unsure whether they were born with a sexual nature, they insisted that they had one. Given that, we have elected to use the term to refer to their sexuality.

${ }^{59}$ (Plummer 1981, p. 72)

${ }^{6 c}$ Although it may appear that these patterns are underlined by the dialectical processes, we do not use the idea of a dialectic in this paper.

${ }^{\circ 1}(1997)$

${ }^{62}$ Here, Stein builds on Ponse's (1978: 61) idea to use the concept "identity work" to grasp the "processes and procedures engaged in by groups designed to effect change in the meanings of particular identities." In contrast to Ponse, Stein (1997: 67) uses this concept to talk about individual women's efforts to "make their subjective sense of self congruent with their emergent social identity as lesbian."

${ }^{{ }^{33}}$ Mike stated that he made this decision in 1980, when AIDS first entered the medical scene. He believed, like everyone else at the time, that AIDS was a gay disease, and his sexual relationships with homosexual men would increase the risk of transmitting the disease to his female partners.

${ }^{6+}$ (Richardson 1996)

${ }^{65}$ (Stein 1997, p. 63)

${ }^{60}$ In this context, we wish to underscore that we can draw on and preserve the subjective perceptions of the actor, in which the individual does not recognize a choice regarding his or her sexuality without falling prey to the problems associated with essentialist interpretations.

\section{ADDITIONAL ESSAYS}

